\title{
Modeling luminal breast cancer heterogeneity: combination therapy to suppress a hormone receptor-negative, cytokeratin 5-positive subpopulation in luminal disease
}

\author{
Aaron J Knox ${ }^{1 \dagger}$, Allison L Scaling ${ }^{1{ }^{*}}$, Mauricio P Pinto ${ }^{1,3}$, Brian S Bliesner ${ }^{1}$, James M Haughian ${ }^{1,4}$, \\ Hany A Abdel-Hafiz ${ }^{1}$ and Kathryn B Horwitz ${ }^{1,2}$
}

\begin{abstract}
Introduction: Many Luminal breast cancers are heterogeneous, containing substantial numbers of estrogen (ER) and progesterone (PR) receptor-negative cells among the ER+ PR+ ones. One such subpopulation we call "Luminobasal" is ER-, PR- and cytokeratin 5 (CK5)-positive. It is not targeted for treatment.

Methods: To address the relationships between ER+PR+CK5- and ER-PR-CK5+ cells in Luminal cancers and tightly control their ratios we generated isogenic pure Luminal (pLUM) and pure Luminobasal (pLB) cells from the same parental Luminal human breast cancer cell line. We used high-throughput screening to identify pLB-specific drugs and examined their efficacy alone and in combination with hormone therapy in mixed-cell tumor models.

Results: We show that pLUM and MCF7 cells suppress proliferation of pLB cells in mixed-cell 3D colonies in vitro and that pLUM cells suppress growth of pLB cells in mixed-cell xenografts in vivo. High-throughput screening of 89 FDA-approved oncology drugs shows that pLB cells are sensitive to monotherapy with the epidermal growth factor receptor (EGFR) inhibitors gefitinib and erlotinib. By exploiting mixed-cell 3D colonies and mixed-cell solid mouse tumors models we demonstrate that combination therapy with gefitinib plus the anti-estrogen fulvestrant constitutes a robust treatment strategy.
\end{abstract}

Conclusions: We propose that response to combination endocrine/EGFR inhibitor therapies in heterogeneous Luminal cancers may improve long-term survival in patients whose primary tumors have been preselected for appropriate biomarkers, including ER, PR, CK5 and EGFR.

\section{Introduction}

Approximately $75 \%$ of breast cancers are luminal. They express estrogen receptors (ER) and/or progesterone receptors (PR) [1], tend to be hormone-dependent and are usually responsive to ER-targeted therapies [2]. Recently a review of immunohistochemical (IHC) ER and PR assays concluded that luminal cancers should be candidates for endocrine therapies if at least $1 \%$ of malignant

\footnotetext{
* Correspondence: Allison.scaling@ucdenver.edu

${ }^{\dagger}$ Equal contributors

'Department of Medicine, Division of Endocrinology, Metabolism and Diabetes, University of Colorado Anschutz Medical Campus, 12801 E. 17th

Ave, Aurora, CO 80045, USA

Full list of author information is available at the end of the article
}

cells are immunoreactive [3]. We asked: in such cases what are the other $99 \%$, presumably receptor-negative, malignant cells? Indeed, the same question applies to less extreme tumors. The ER frequency distribution in 825 sequential breast cancers over a 2-year period [4] shows that although $81 \%$ of tumors are ER-positive (ER+), $30 \%$ to $80 \%$ of their cells are ER-negative (ER-). Analyses of 1,235 breast cancers [5] show PR distribution to be even more varied, with approximately $50 \%$ of $\mathrm{PR}+$ tumors containing a significant proportion of PR- cells. Thus, most luminal tumors exhibit intratumoral heterogeneity containing substantial numbers of ER- and PR - cells among the ER+ and/or PR+ ones.

Intertumoral heterogeneity is well-known with breast cancer subtypes classified based on clinical and histopathological 
features, or gene expression profiles [6]. Major subtypes defined by gene profiling include luminal, human epidermal growth factor receptor-2-positive (HER2+) and basallike. However, routine gene profiling is limited [7], and as all transcripts are pooled, the assay does not lend itself to analysis of intratumoral heterogeneity. Instead, five protein markers - ER, PR, HER2, Cytokeratin 5 (CK5) and epidermal growth factor receptor-1 (EGFR) - can serve as surrogates to classify breast cancers into subtypes analogous to those defined by gene profiling. Using these markers, IHC analysis of 10,159 invasive breast cancers collected from 12 studies [8] showed that in addition to $77 \%$ of tumors classified as luminal based on ER and/or PR positivity, approximately $6 \%$ are non-luminal but overexpress HER2 protein or its amplified gene [9], and approximately $16 \%$ are basal-like or triple-negative (TN) because they lack ER, PR and HER2. TN tumors were further subclassified into approximately $9 \% \mathrm{CK} 5+$ and/or EGFR+ and approximately 7\% were negative for all five markers. Clearly, such detailed intertumoral classification is important because each subtype responds differently to endocrine-, immuno- or chemotherapies, and each has a different long-term fate, with basal-like tumors generally characterized by heightened aggressiveness compared to luminal or HER2+ tumors.

Theories on the origins of intra- and intertumoral heterogeneity [10] include: rise of subclones from precursors that subsequently accrue genetic changes; stochastic gene expression patterns generating random signaling pulses; or cellular reprogramming by semi-stable imprinting of epigenetic tags [11]. The evolution and population frequency of modified subclones would then be regulated by the age and diagnostic stage of the tumor, differential growth rates, microenvironmental signals, cell-cell interaction dynamics, therapeutic interventions, and the like. There is also speculation based in part on the tissue organization of normal breast epithelium into luminal and basal elements, that the origins of intertumoral heterogeneity might be traced to normal stem cells that underlie these structures. If so, perhaps as also hinted at by expression profiling, one might speculate that the two major breast cancer subtypes - luminal and basal-like - should have negligible genomic kinship.

We find however, that the distinctions between intraand intertumoral heterogeneity are not clear-cut. Recently we analyzed a series of luminal breast cancers using two markers - luminal PR and basal CK5 [12]. Four theoretical cell populations are possible and all were observed: $\mathrm{PR}+\mathrm{CK} 5$ - cells (luminal); PR-CK5+ cells (we dubbed luminobasal); cells lacking both markers (double-negative); and rare $\mathrm{PR}+\mathrm{CK} 5+$ cells (double-positive). We also observed that more than $50 \%$ of luminal cancers contain luminobasal cells; that neoadjuvant endocrine therapies increase luminobasal-cell number in both hormone-responsive and hormone-resistant patients; and that in experimental models luminobasal-cell expansion can be blocked by inhibition of Notch signaling [13]. In retrospect, resistance of luminobasal cells to endocrine therapies is not surprising as they lack ER and PR and cluster with basal-like tumors. These facts suggested to us that presence of luminobasal cells in luminal disease might be dangerous and they needed to be targeted for treatment.

To define relationships between luminal and luminobasal cells and assess the therapeutic vulnerabilities of luminobasal cells, we have generated pure luminal (pLUM; ER+ $\mathrm{PR}+\mathrm{CK} 5-$ ) and pure luminobasal (pLB; ER-PR-CK5+) cell lines derived from solid T47Dco tumor xenografts. We characterize them, describe their biological properties when pure or mixed in three-dimensional colonies or as solid tumor xenografts, and use high-throughput screening to demonstrate that the pLB subpopulation is sensitive to EGFR inhibitors (EGFRi). We demonstrate that simultaneously targeting pLUM and pLB in mixed-cell tumors in vivo and three-dimensional colonies in vitro with a combination of the anti-ER fulvestrant plus the EGFRi gefitinib may constitute a robust treatment strategy for heterogeneous primary luminal disease expressing the appropriate biomarkers.

\section{Methods \\ Cell lines}

MCF-7 human breast cancer cells were from Sam Brooks (Michigan Cancer Foundation, Detroit); T47D cells were from Iafa Keydar (Tel Aviv University, Israel); the T47Dco subline was described in Horwitz et al. [14]. All cell lines have been authenticated by STR analysis and are mycoplasma-free.

\section{Generation of pLUM and pLB}

All animal studies were approved by the University of Colorado Institutional Animal Care and Use Committee (approval number 91212 (02) 1E). Briefly, wild-type T47Dco cells in Matrigel were injected into cleared mammary fat pads of pre-pubertal ovariectomized (ovx'd) NOD SCIDY (NSG) mice (NCI, Frederick, MD, USA or Jackson Laboratories, Bar Harbor, ME, USA) and implanted with cellulose (E withdrawn, EWD), $2 \mu \mathrm{g} 17 \beta$-estradiol (E), or $\mathrm{E}+8 \mu \mathrm{g}$ progesterone $(\mathrm{E}+\mathrm{P})$-containing pellets [13]. Three-month old tumors were minced, rotated with collagenase, DNAse and hyaluronidase followed by red blood cell lysis. Cells were plated in phenol-red free DMEM (Gibco) containing 5\% charcoal-stripped fetal bovine serum (FBS) in EWD or $1 \mathrm{nM}$ E-supplemented conditions.

To generate pLUM, cells from an E-tumor were propagated in vitro for approximately 2 months in $1 \mathrm{nM} \mathrm{E}$. Live cells were sorted by fluorescence-activated cell sorting (FACS) (Moflo XDP 100, Beckman Coulter, Indianapolis, IN, USA) using CLD3 and CD49f to separate luminal (CLD3+ CD49f-) from luminobasal (CLD3- CD49f+) cells. 
The CLD3+ CD49f- population was replated, cultured for approximately 2 months more in $\mathrm{E}$ and re-sorted twice to generate pure pLUM (CLD3+ CD49f-). They were maintained in E-containing medium and remained luminobasalfree. To generate $\mathrm{pLB}$, cells from an $\mathrm{E}+\mathrm{P}$ tumor were plated in vitro for approximately 2.5 months under EWD conditions. They were sorted by FACS and the CLD3CD49f + subpopulation was re-cultured for approximately 2 months more under EWD conditions then re-sorted twice to yield pure pLB (CLD3- CD49f + ). They were maintained in EWD media and remained luminal-free. Both cell lines were authenticated by STR and are mycoplasmafree. Maintenance of pLUM and pLB states is monitored by IHC for a series of marker proteins (Table 1). Aliquots have been stably tagged with ZsGreen (ZsG) fluor [15].

\section{Expression profiling}

Briefly [16], $72 \mathrm{~h} 1 \mathrm{nM}$ E-treated pLUM; EWD pLB; and E plus $100 \mathrm{nM}$ P-treated T47Dco cells were suspended (Accumax; Millipore, Billerica, MA, USA), fixed, permeabilized with RNAlater (Ambion Inc., Ambion, Foster City, CA, USA) and incubated with anti-CK5 labeled with Zenon Alexa Fluor 488 (Invitrogen, Grand Island, NY, USA; $\mathrm{Z}-25002)$. Stained cells were centrifuged and resuspended in RNAse-free NST buffer containing 4',6-diamidino-2-phenylindole (DAPI), and CK5+ versus CK5 - cells sorted by FACS (Beckman-Coulter XDP-100 MoFlo). Separated cells

Table 1 Characterization of pure luminobasal (pLB) and pure luminal (pLUM) cells

\begin{tabular}{|c|c|c|c|}
\hline \multirow[b]{2}{*}{ Factors } & \multicolumn{2}{|c|}{ Immunohistochemistry } & \multirow{2}{*}{$\begin{array}{l}\text { mRNA } \\
\text { Fold pLB versus pLUM }\end{array}$} \\
\hline & pLB & pLUM & \\
\hline CK5 & +++ & - & $+7,336$ \\
\hline Jag1 & + & - & +809 \\
\hline Annexin A1 & +++ & + & +405 \\
\hline EGFR & ++ & - & +146 \\
\hline Slug (SNAI2) & + & - & +103 \\
\hline p63 (TP63) & ++ & - & +65 \\
\hline CD49f (Itga6) & +++ & - & +23 \\
\hline $\mathrm{p}$-Cadherin $(\mathrm{CDH} 3)$ & ++ & - & +20 \\
\hline Notch-1 & + & - & +8 \\
\hline CD44 & ++ & - & +1.3 \\
\hline CK8/18 & + & +++ & -3 \\
\hline FOXA1 & - & ++ & -5 \\
\hline GATA3 & - & ++ & -46 \\
\hline$E R$ & - & ++ & -70 \\
\hline Claudin-3 & - & ++ & -113 \\
\hline Muc1 & - & ++ & -118 \\
\hline PR & - & ++ & -189 \\
\hline
\end{tabular}

CK5, cytokeratin 5; EGFR, epidermal growth factor receptor; ER, estrogen receptor; PR, progesterone receptor. were collected, centrifuged, and resuspended, and RNA was extracted (PicoPure; Arcturus/Life Technologies, Carlsbad, CA, USA). RNA from triplicate sorts was profiled using Agilent $4 \times 44 \mathrm{~K}$ chips. Labeling, hybridization and initial analyses were performed at MOGENE LC, St. Louis, MO, USA. All microarray data can be accessed in the Gene Expression Omnibus database [GSE55350; GEO].

\section{Mixed-cell xenografts}

pLUM $\left(5 \times 10^{5}\right)$, ZsG-pLB alone, or 5:1 mixtures of pLUM: ZsG-pLB in Matrigel were injected into cleared mammary fat pads of ovx'd NSG mice implanted with cellulose (EWD) or E pellets. Tumor growth was quantified weekly for 8 weeks. At necropsy, tumors were resected, fixed in $4 \%$ paraformaldehyde, paraffin-embedded and processed for IHC. Paraffin sections were stained with DAPI, tumor boundaries were defined, scanned for ZsG fluorescence (Nikon T1 Eclipse) and quantified (NIS-Elements software; Nikon, Melville, NY, USA). For combination therapy experiments, $5 \times 10^{5}$ pLUM, pLB alone, or 1:1 pLUM:pLB mixtures in Matrigel were injected as described above. Control 6 wk-old tumors generated from 1:1 mixtures were treated for 10 days with vehicles, gefitinib $(100 \mathrm{mg} / \mathrm{kg}$ daily in $1 \%$ Tween; oral gavage), Fulvestrant (50 mg/mouse on days 1 and 6 in 10\% ethanol and sesame oil; subcutaneously), or both. Tumor volumes were quantified every $48 \mathrm{~h}$.

\section{Mixed cells in vitro}

pLB $\left(5 \times 10^{4}\right)$ or pLUM alone, or as $5: 1,3: 1,1: 1,1: 3$ or $1: 5$ pLUM:pLB ratios, were plated in E-free, growth factor (GF)-reduced Matrigel and grown into three-dimensional colonies for 7 days [17]. Alternatively, pLUM, pLB and MCF7 cells alone or as 1:1 or 5:1 pLUM:pLB or MCF7:pLB ratios were established over $24 \mathrm{~h}$ then treated for 7 days with: a) vehicles; b) $100 \mathrm{nM}$ fulvestrant; c) $1 \mu \mathrm{M}$ gefitinib on days 6 and 7; or d) fulvestrant plus gefitinib on days 6 and 7. Colonies were incubated for $1 \mathrm{~h}$ with bromodeoxyuridine (BrdU; Sigma, St. Louis, MO, USA), and Matrigel blocks were sandwiched between HistoGel, paraffinembedded and sectioned for IHC [17].

\section{Immunohistochemistry (IHC)}

Serial $4-\mu \mathrm{m}$ sections were stained by dual IHC and DAPI for relevant luminal, basal, luminobasal and proliferation markers. Antibodies and sources are listed in Additional file 1: Table S1. Sections were photographed (Nikon Eclipse E600 fluorescence microscope) and cell subpopulations quantified (Image Pro 4.5; Media Cybernetics, Rockville, MD, USA). A BrdU index (BrdU+ nuclei in CK5+ or CK5cells versus DAPI+ nuclei) was calculated from five random $100 \times$ (three-dimensional colonies) or $400 \times$ (xenografts) fields/condition. 


\section{Cell-conditioned media}

Cell-free (C) or pLB, pLUM or MCF7 cells were cultured to $50 \%$ to $60 \%$ confluence in DMEM with $5 \%$ FBS, then washed and incubated for $48 \mathrm{~h}$ in phenol redfree DMEM and charcoal-stripped FBS. Conditioned media (CM) were purged of cellular elements by filtration $(0.2 \mu \mathrm{M})$. Separately, cells were grown for $48 \mathrm{~h}$ as three-dimensional Matrigel colonies in multiwall chambers. Medium was discarded and colonies were reincubated with $\mathrm{C}$ or $\mathrm{CM}$ for an additional $48 \mathrm{~h}$. Unfixed colonies were photographed (Nikon Eclipse E600) and cluster diameters were quantified from $100 \times$ brightfield images (Nikon NIS Elements).

\section{High-throughput drug screening}

Mixtures (1:1) of ZsG-pLB $\left(10^{4}\right)$ and untagged pLUM $\left(10^{4}\right)$ were cultured for $24 \mathrm{~h}$ in triplicate 96-well plates in EWD or $2 \mathrm{nM}+\mathrm{E}$ conditions, then treated for $48 \mathrm{~h}$ with $0.05 \%$ DMSO or $1 \mu \mathrm{M}$ drug from the 89-drug NCI-DTP Approved Oncology library (Additional file 2: Table S2). Media were aspirated, cells were fixed and immunostained with antiCLD3, and counterstained with DAPI. Total (blue), pLUM (red) or pLB (green) subpopulations were imaged and quantified at 20x. Nine fields/well were captured (Additional file 3: Figure S1) averaging 8,000 cells/field in controls.

\section{Statistical analysis}

Data were quantified as the mean \pm standard error (SEM) of three or more separate experiments, and analyzed with Prism 6.0 (Graphpad Software, Lo Jolla, CA, USA) using one way analysis of variance (ANOVA) or Student's $t$-test. Differences with $P \leq 0.05$ were considered to be significant.

\section{Results}

Generation of pLUM and pLB cells

We recently isolated two cell lines from luminal T47Dco xenografts grown in ovx'd NSG mice: EWD8 consisting mainly of luminobasal ER-PR-CK5+ cells derived from a tumor in EWD mice; and E3 consisting mainly of luminal $\mathrm{ER}+\mathrm{PR}+\mathrm{CK} 5-$ cells derived from a tumor in Ereplenished mice [13]. Gene profiling, confirmed by IHC showed that CD49f expression was unique to EWD8 and CLD3 expression was unique to E3 [13]. Antibodies against these two proteins were used here for sequential dual FACS of another set of T47Dco mouse tumorderived cells to generate two new, isogenic, pure cell lines: pLB are CLD3- CD49f+ and ER-PR-CK5+; pLUM are CLD3+ CD49f- and ER+PR+CK5- (Figure 1). Despite originating from the same parental cells each line exhibits a distinct gene signature (Additional file 4: Figure S2). pLB cells are propagated in vitro under EWD conditions; pLUM cells are propagated under E-replete conditions. Both have been tagged with ZsGreen [18].

To confirm markers unique to pLB or pLUM, expression of a 17-protein subset selected from the luminobasal gene signature [13] was assessed by IHC (Table 1). Proteins that marked pLB but not pLUM include CK5, Jag1, AnnexinA1, EGFR, Slug, p63 and CD49f; proteins that marked pLUM but not pLB include ER, PR, MUC1, CLD3, GATA3 and FOXA1. This confirms gene profiling transcript data (Table 1), the luminal assignment of pLUM, and the luminobasal assignment of pLB, which cluster with basal cells and tumors [13] but retain luminal markers like CK8/18. Like their parental cells, neither pLUM nor pLB express HER2 protein (not shown).

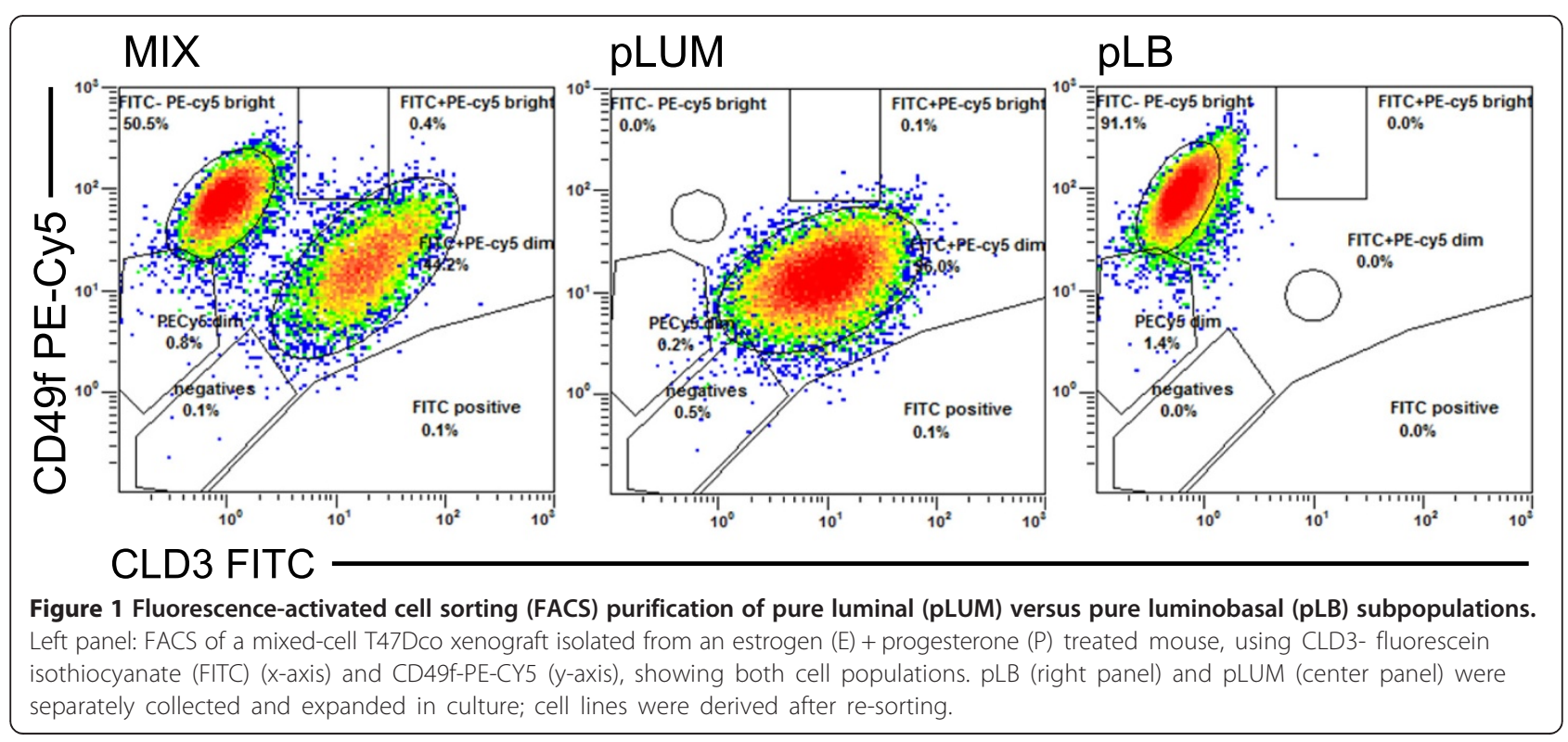




\section{Mixed-cell xenografts: pLUM cells suppress neighboring pLB cells}

Most luminal tumors are heterogeneous, composed of cell mixtures including ER-PR-CK5+ luminobasal cells [12]. Because in TN disease luminobasal-like cells are highly aggressive we expected that in mixed luminal
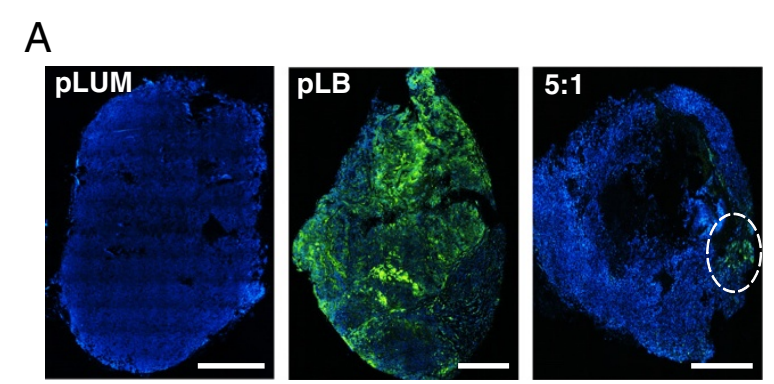

B
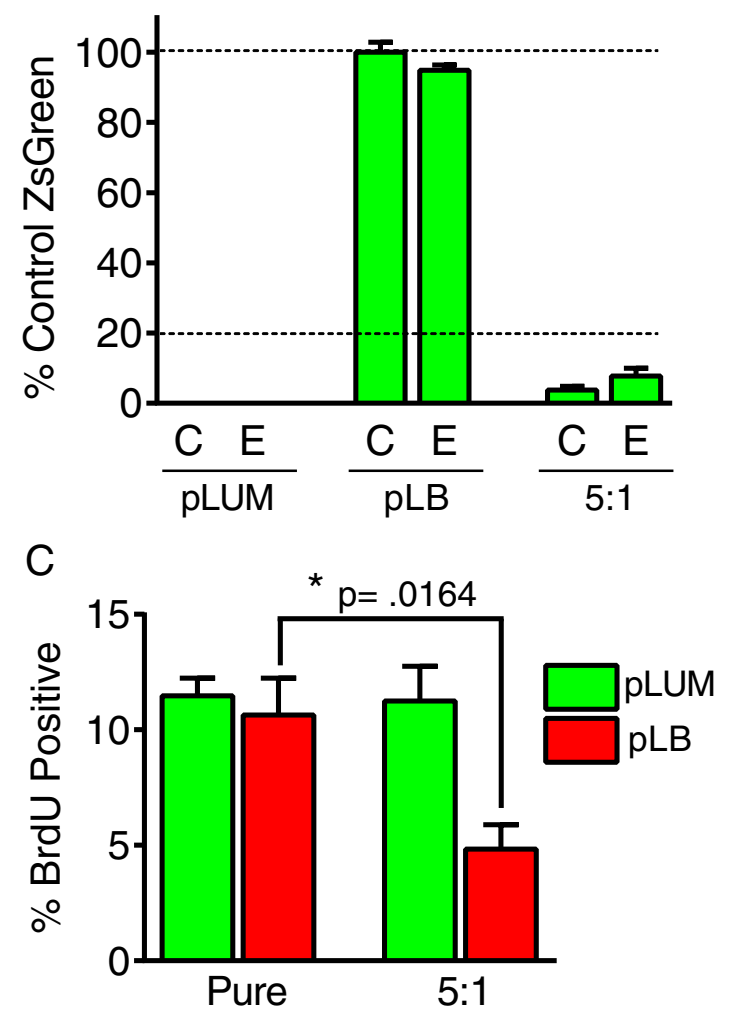

Figure 2 Pure luminal (pLUM) suppress proliferation of neighboring pure luminobasal ( $\mathrm{pLB}$ ) in mixed-cell xenografted solid tumors. (A) Whole-tumor cross-sections of untagged pLUM ZsGreen (ZsG)-pLB and 5:1 pLUM:pLB xenografts grown in ovariectomized mice without hormones. Tumor sections counterstained with 4',6-diamidino-2-phenylindole (DAPI) (blue). Scale bars equal $2000 \mu \mathrm{M}$. (B) Quantitation of ZsG fluorescence in pLUM, pLB and 5:1 pLUM:ZsG-pLB tumors relative to fluorescence of pure ZsG-pLB tumors under control (C) or estrogen (E) conditions. (C) Proliferation rates quantified by bromodeoxyuridine (BrdU) incorporation of pLUM and ZsG-pLB subpopulations in pure and mixed-cell tumor xenografts. Percent BrdU + cells in CK5 - and CK5 + cells were quantified for $\geq 5$ independent tumors; ${ }^{*} P \leq 0.05$. tumors the pLB subpopulation would eventually become dominant. However, in both luminal disease and in vitro models, ER-PR-CK5+ cells are indolent; proliferating more slowly than their ER+PR+CK5- neighbors [12]. To show if pLUM cells suppress nearby pLB cells the pure cell lines were used to control the ratio of each subpopulation in mixed-cell xenografts. Figure 2 shows data for 8week-old tumors grown from pLUM, ZsG-pLB or a 5:1 pLUM:ZsG-pLB mixture in ovx'd mice without (C) or with $\mathrm{E}$ supplementation. The pure cell lines yield relatively pure tumors (green pLB or untagged pLUM) of each cell type (Figure 2A). However regardless of the hormonal state (Figure 2A, B) in 5:1 mixed pLUM:ZsG-pLB implants, the number of green pLB cells was significantly $(P=0.0164)$ suppressed. Despite starting at $20 \%$ of the population, only $4 \%$ to $8 \%$ of cells were pLB at necropsy (Figure 2B). Mixed-cell tumors tended to enlarge rapidly but had extensive necrotic centers and the rare pLB cells aggregated to tumor fringes (Figure 2A). Evidence for pLB suppression by pLUM cells was confirmed by BrdU quantitation (Figure $2 \mathrm{C}$ ) showing that even in the absence of $\mathrm{E}$ (conditions in which luminal cells are unstimulated) pLUM cells suppress PLB proliferation.

\section{Mixed cells in vitro}

To address mechanisms for pLB suppression by pLUM, single-cell suspensions of pLUM and pLB cells either alone or mixed in pLUM:pLB 5:1, 3:1, 1:1, 1:3 or 1:5 ratios were grown as three-dimensional colonies under EWD conditions [17]. Seven-day colonies were incubated with BrdU, sectioned and dual-stained for BrdU plus luminal CK8/18 or basal CK5 to mark each subpopulation (Figure 3). Note that despite having been introduced into Matrigel comingled, cells aggregate by type with mixed-cell colonies characteristically having a pLB core surrounded by pLUM (Figure 3A, top). In general, pLUM cells have a higher proliferation rate than pLB cells (Figure $3 \mathrm{~A}$ bottom, B), and pLB proliferation progressively shrinks as the proportion of pLUM rises (Figure 3B). At 5:1 pLUM:pLB ratios proliferation of pLB is reduced by approximately $81 \%$ $(P<0.0001)$ compared to pLB controls.

To demonstrate that suppression by pLUM of pLB is a general phenomenon, the three-dimensional mixed-cell colony assay was repeated substituting classic luminal $\mathrm{ER}+\mathrm{PR}+\mathrm{MCF}-7$ cells for pLUM (Figure 3C). MCF-7 cells are powerful suppressors, progressively reducing pLB proliferation with $97 \%(P<0.0001)$ pLB suppression at the 5:1 MCF-7:pLB excess.

As mixed cells segregate by subtype within colonies and tumors with minimal direct PLUM and pLB cell-cell contact, we speculated that pLUM suppress $\mathrm{pLB}$ via a diffusible factor. To test this, pLB, pLUM or MCF-7 cells growing as three-dimensional colonies were incubated with media previously conditioned (CM) by pLB, pLUM 


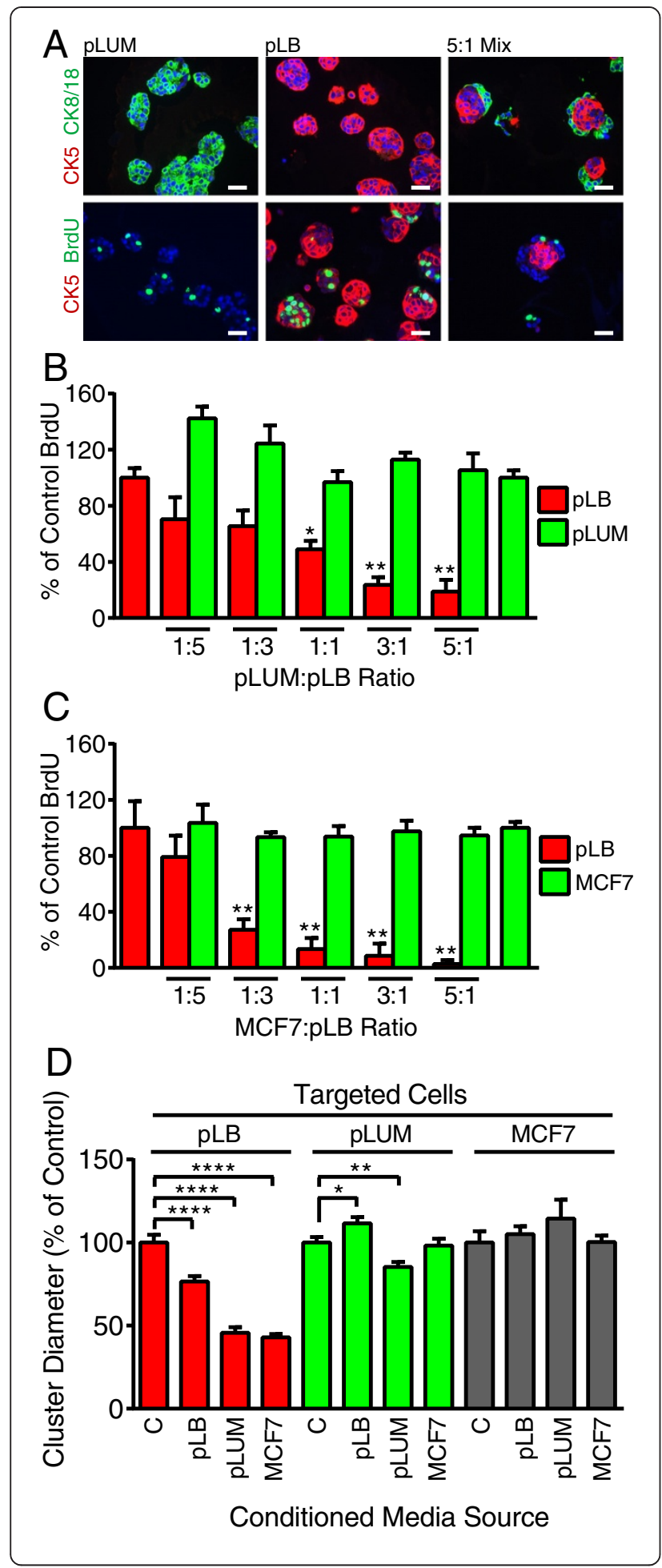

Figure 3 Pure luminobasal (pLB) proliferation is suppressed by pure luminal (pLUM) cells via a diffusible factor. pLUM, $P L B$ and ratios of PLUM:pLB cell mixtures were seeded onto solidified growth factor (GF)-reduced Matrigel. Three-dimensional colonies were cultured for 7 days in hormone-free conditions. Bromodeoxyuridine (BrdU) was added, Matrigel blocks were sandwiched between HistoGel, paraffin-embedded and sectioned for immunohistochemistry (IHC). (A) Sections dual stained for CK5 (red) and CK8/18 or BrdU (green), counterstained with 4',6-diamidino-2-phenylindole (DAPI) (blue). Scale bars equal $20 \mu \mathrm{M}$. (B) Quantitation of BrdU incorporation into pLB or pLUM cells in pure cells (set at 100\%) or mixed-cell colonies. (C) Same as A and B, but MCF-7 were substituted for pLUM. (D) Media-conditioned (CM) by no cells (control), or by pLB, pLUM or MCF7 cells growing in 2D on plastic, were collected. Separately, pLB, pLUM or MCF-7 cells were grown as three-dimensional Matrigel colonies in regular media for $48 \mathrm{~h}$, then switched to the CM media shown for $48 \mathrm{~h}$. Colonies were photographed and their diameters in $C M$ were compared to colony diameters in control media; ${ }^{*} P \leq 0.05$; ${ }^{* *} P \leq 0.01 ;{ }^{* * *} P \leq 0.001 ;{ }^{* * *} P \leq 0.0001$.

or MCF-7 cells grown on plastic. Compared to control cell-free medium, pLUM (Figure 3D) or MCF-7 CM (not shown) significantly reduced the size of pLB colonies by $>50 \%(P<0.0001)$ whereas pLB CM had little effect on pLUM or MCF-7 (Figure 3D) colonies. This suggests that diffusible inhibitory factor(s) released by luminal cells suppress proliferation of nearby luminobasal cells.

\section{pLB cells are selectively targeted by EGFR inhibitors}

In mixed-cell hormone-dependent tumors, luminobasal cells are intrinsically hormone- and chemotherapy-resistant $[12,13]$. This scenario may be acceptable in untreated cancers containing few luminobasal cells. The danger arises when the number of luminobasal cells expands as ERtargeted therapies reduce luminal cell number [12]. We therefore suspect that luminobasal cells should be treated in primary tumors. To identify drugs that selectively do so, the 89-drug NCI-DTP Approved Oncology library (Additional file 2: Table S2) was screened. It contains hormone antagonists, chemotherapeutic agents, targetbased kinase inhibitors and epigenetic/histone acetylationmodifying drugs in current clinical use. A high-throughput screen used fluorescent imaging to quantify ZsG-pLB cells and CLD3+ pLUM cells plated in 1:1 mixtures. Cells were pretreated for $24 \mathrm{~h}$ under EWD or $+\mathrm{E}$ conditions (Additional file 3: Figure S1), after which pLB comprised $45 \%$ of cells in EWD wells and $39 \%$ in $+E$ wells. While EWD or $+E$ were continued, the cells were exposed to drugs for $48 \mathrm{~h}$. Figure $4 \mathrm{~A}$ summarizes the number of pLB (red), pLUM (green) and \% pLB (black) compared to vehicle controls under $+\mathrm{E}$ conditions. Extensive nonspecific cytotoxicity for both cell types was induced by chemotherapeutic agents such as vincristine, azacytidine, gemcitabine, mithramycin, et cetera. However, selective and targeted reduction of the pLB subpopulation (note the drop in \% black pLB bars with conservation of green pLUM bars) 


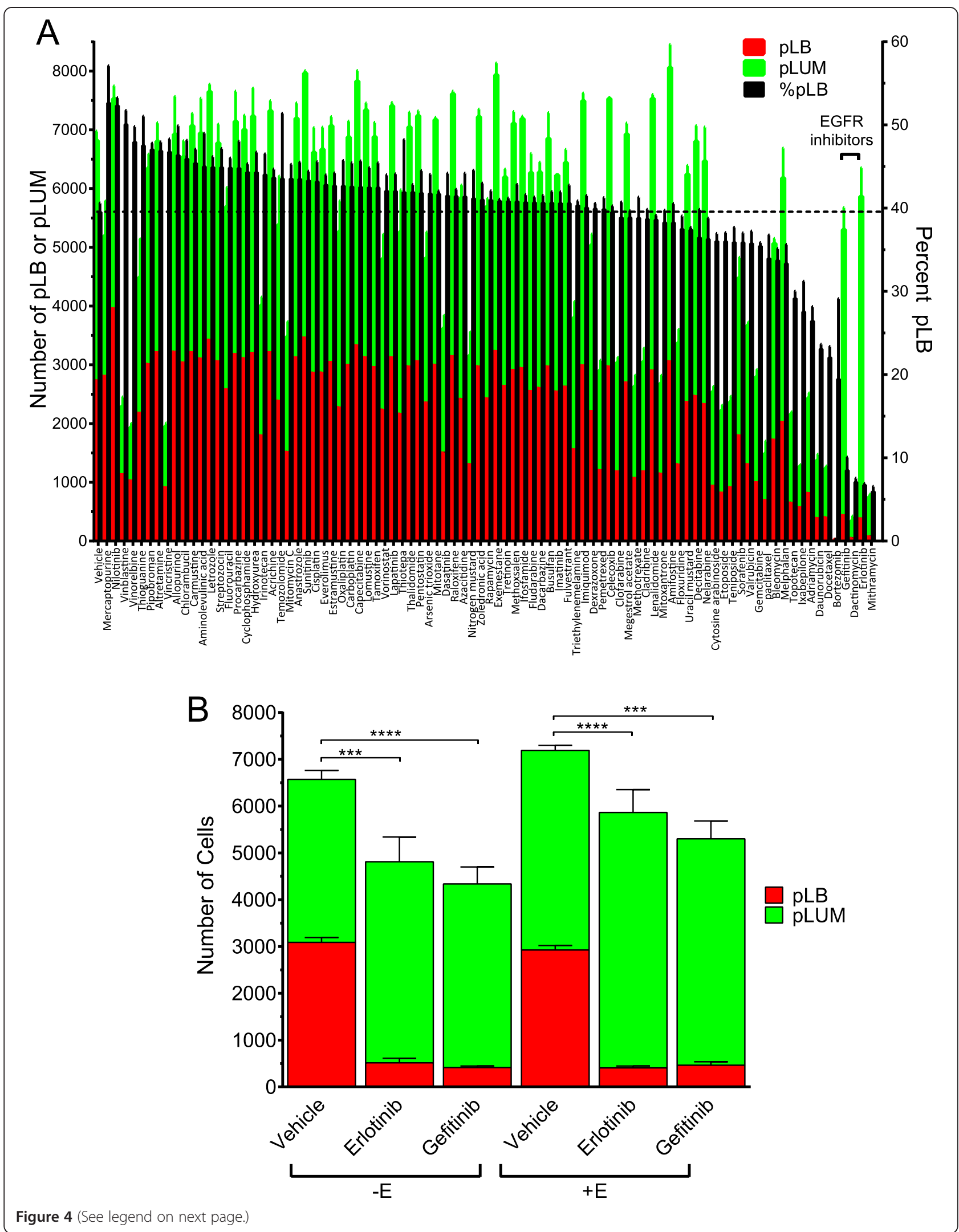


(See figure on previous page.)

Figure 4 High-throughput screening: targeting pure luminobasal (pLB) cells with drugs from an $\mathrm{NCl}$-approved 89-drug oncology library. (A) 1:1 mixtures of pLUM:ZsG-pLB were co-cultured in triplicate 96-well plates in 1 nM 17ß-Estradiol (E; not shown, see panel B) or E-free (shown) conditions, then treated $48 \mathrm{~h}$ with a panel of $89 \mathrm{NCl}$-approved oncology drugs $(1 \mu \mathrm{M})$ or $0.05 \%$ dimethyl sulfoxide (DMSO) controls. Media were aspirated, cells were fixed, immunostained for CLD3 (red) and counterstained with 4',6-diamidino-2-phenylindole (DAPI) (blue). Total (blue), pure luminal (pLUM) (red) or pLB (ZsG, green) subpopulations were imaged and quantified at 20x. There were 9 fields/well captured, averaging 8,000 cells/field in controls (Additional file 3: Figure S1A). Mean numbers of pLB (red bars) and pLUM (green bars) cells, and \% pLB (black bars) are shown as the average of triplicates \pm standard error of the mean (SEM). Erlotinib, $P \leq 0.0001$, gefitinib, $P=0.0005$. (B) Details of vehicle, erlotinib or gefitinib data from panel $A$ in both + E and $-E$ conditions; ${ }^{* *} P \leq 0.001 ;{ }^{* * *} P \leq 0.0001$ for $p L B$ cell numbers in gefitinib or erlotinib versus vehicle control.

was observed with the anti-EGFR small molecule inhibitors gefitinib and erlotinib (Figure 4A). Detailed analyses under both EWD and + E conditions (Figure 4B) showed that after $48 \mathrm{~h}$ gefitinib reduced the pLB subpopulation from $45 \%$ to 9\% (EWD) $(P \leq 0.0001)$ and from $39 \%$ to $9 \%(+\mathrm{E})(P=$ $0.0005)$. Similarly, erlotinib reduced the pLB subpopulation to $10 \%(E W D)(P=0.0001)$ and $7 \%(+E)(P \leq 0.0001)$. Neither drug influences the pLUM subpopulation.

The reliance on EGFR signaling correlates with upregulation of EGFR in pLB cells [13] (Table 1; Additional file 5: Figure S3). Interestingly, during the $48 \mathrm{~h}$ treatment time the dual HER2/EGFR inhibitor lapatinib, currently in use for second-line therapy of herceptin-resistant ER+EGFR+ HER2+ breast cancers, did not reduce the pLB subpopulation, consistent with the fact that HER2- tumors (like pLB) tend to be unresponsive to this drug [19]. Additionally, nilotinib, a $b c r-a b l$ inhibitor produced an unexpected and significant increase in the proportion of pLB cells, an effect that requires further study. Lastly, the pLUM subpopulation was unaffected by the endocrine therapeutic drugs present in the library. In our experience, in 2D conditions like those used here these require a longer treatment window (but see 3D, Additional file 6: Figure S4).

\section{Combination anti-ER/anti-EGFR therapy targets both populations in mixed-cell tumors}

Our goal is to proffer combination therapies that target luminal and luminobasal subpopulations in heterogeneous $\mathrm{ER}+\mathrm{PR}+$ disease. We tested gefitinib in combination with fulvestrant (ICI 182, 780; ICI) using 1:1 or 5:1 pLUM:ZsG-pLB mixtures in three-dimensional colonies (Figures 5, Additional file 6: Figure S4A) treated with vehicle, ICI (100 nM), gefitinib $(1 \mu \mathrm{M})$ or ICI + gefitinib. BrdU was added prior to harvest, colonies were fixed, sectioned and stained for CLD3, CK5 and BrdU, photographed and a BrdU index/cell type was quantified. Gefitinib completely suppressed pLB proliferation with no effect on pLUM. ICI significantly reduced PLUM with no significant effect on pLB. Combining the drugs showed no influence of one on the other (Figure 5A). Drug effects in 1:1 and 5:1 pLUM:pLB colonies were highly effective: the combination decreased proliferation in 1:1 pLUM:pLB colonies by 88.5\% $(P<0.0001)$, and in $5: 1$ colonies by $95 \%(P<0.001)$. Additionally the cell heterogeneity exposed effects of one cell type on the other. For example, suppression of pLUM by ICI monotherapy paradoxically increased $\mathrm{pLB}$ proliferation in the absence of gefitinib by removing the pLUM-secreted inhibitor (Figure 3). We argue that this can be prevented in cell mixtures by combination therapies that target both cell types. In sum the data point to the value of targeting two cell subpopulations in a tumor, and provide an illustration that monotherapy targeting one subpopulation, can have the unintended consequence of allowing the other to expand.

To demonstrate that this outcome was not restricted to one cell line, we substituted MCF-7 cells for pLUM cells (Figure 5B). This shows again the marked suppressive effects of MCF-7 cells on proliferation of neighboring $\mathrm{pLB}$ cells even without treatment, the further proliferative suppression of pLB by gefitinib, and the efficacy of the combination therapy in reducing overall colony cell growth. Photographs of representative colonies stained for CK5 (red), BrdU (green) and total cells (blue) are shown for pLUM:pLB (Additional file 6: Figure S4A) and MCF-7: pLB (Additional file 6: Figure S4B). Note for example that gefitinib completely shuts down proliferation of pure $\mathrm{pLB}$ colonies (panel 5); or that only luminal cells in mixed colonies proliferate with combination therapies (panel 16).

We then tested a gefitinib/ICI combination in heterogeneous solid tumors in vivo (Figure $5 \mathrm{C}$ ). For this $5 \times 10^{5}$ pLUM, pLB or a 1:1 pLUM:pLB mixture was injected into cleared mammary fat pads of ovx'd mice without hormone supplementation and grown into tumors for 6 weeks. Since pLUM cells suppress pLB cells (Figures 2 and 3) the 1:1 ratio was chosen so that sufficient numbers of pLB cells would remain in 6-week-old tumors to allow their quantitation despite further EGFRi suppression. Six-week tumorbearing mice were administered vehicle controls, ICI (5 mg/mouse; days $6+10)$, gefitinib (100 mg/kg, once daily), or ICI + gefitinib for 10 days. Tumor sizes were measured every $48 \mathrm{~h}$. Tumors continued to expand in controls during 10 days; they were modestly reduced by ICI (which requires longer treatment times) and significantly reduced by gefitinib alone $(P=.0005)$ or the gefitinib + ICI combination $(P=.0002)$. These data demonstrate that EGFRi can target LB cells even in the presence of an anti-estrogen.

\section{Discussion}

\section{Hormone resistance}

Treatments for luminal breast cancer exploit its ERpositivity and estrogen dependence by disrupting estrogen signaling, downregulating the ER or reducing E production. 


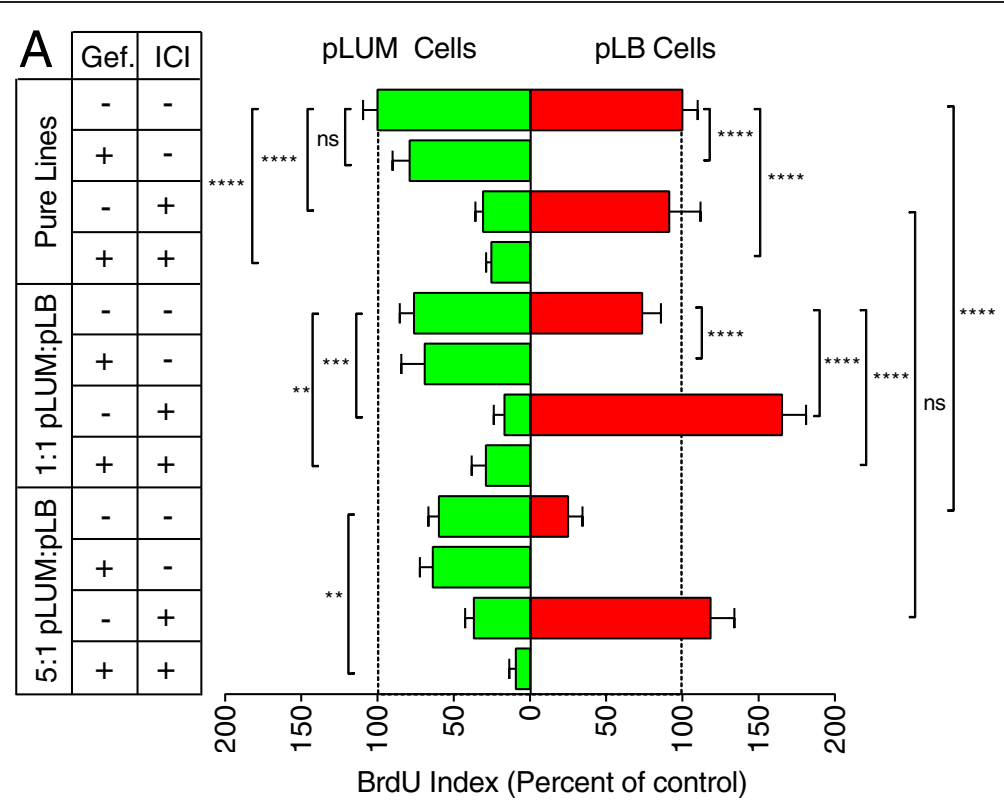

B
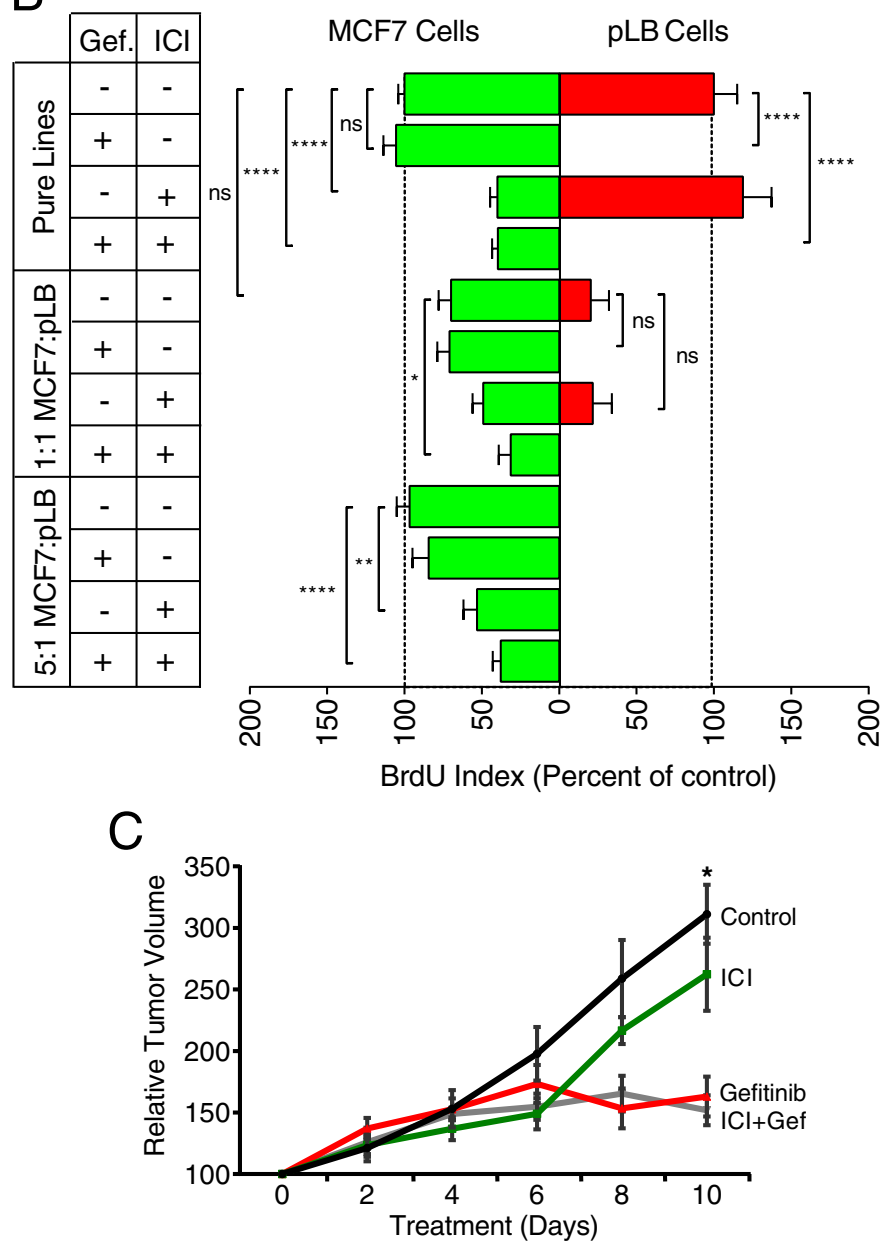

Figure 5 (See legend on next page.) 
(See figure on previous page.)

Figure 5 Combined targeting of pure and mixed-cell pure luminal (pLUM) and pure luminobasal (pLB) colonies with fulvestrant/gefitinib. (A) Pure pLUM, pLB or 1:1 and 5:1 pLUM:pLB mixtures were grown as three-dimensional Matrigel colonies in the absence of hormones for 48 h. Colonies were switched for 5 days to media containing no drug (days 1 to 5); 1 uM gefitinib (days 4 to 5); 100 nM ICl (days 1 to 5); or both (ICl days 1 to 5; gefitinib days $4+5)$. Colonies were treated with bromodeoxyuridine (BrdU), processed for immunohistochemistry (IHC) and a BrdU proliferation index was quantified. Data are average of triplicates \pm standard error of the mean (SEM). ${ }^{*} P \leq 0.05$; ${ }^{* *} P \leq 0.01,{ }^{* * *} P \leq 0.001,{ }^{* * *} P \leq 0.0001$, ns, not-significant. (B) Same as $\mathbf{A}$ except MCF-7 cells were substituted for pLUM. (C) 1:1 mix of pLUM:pLB cells was injected into cleared fat pads of ovariectomized non-obese diabetic/severe combined immunodeficient (NSG) mice and tumors were grown 6 weeks without hormones. Mice were treated 10 days with no drug (Control), fulvestrant (ICI), gefitinib or both. Tumor volumes are expressed as \% volume on treatment day 0 , for $\geq 4$ tumors \pm SEM at each time point.

Patients with luminal disease respond well initially, but long-term survival declines steadily after 5 years and eventually falls below that of basal-like cancers [20,21]. Mechanisms underlying luminal tumor recurrence are varied. Explanations include development of acquired resistance through genetic or epigenetic pathways that target ER signaling or upregulate growth factor escape, or pre-existing resistance due, for example, to mutant ER [22]. All likely apply to subsets of patients. However, directly or indirectly all assume that ER+ cells - either early or late in luminal tumor evolution - undergo the molecular changes linked to resistance. The present study focused on an alternative mechanism, namely that many primary luminal tumors are heterogeneous at diagnosis, containing ER- cells that lack the molecular machinery to respond to endocrine therapies. Although the origins of ER- cells in luminal disease remain under intense study [23], we argue that such cells cannot be ignored and should be treated along with their ER+ neighbors. Indeed we have shown in both clinical and experimental settings that targeting only the ER+ subpopulation has the unintended consequence of increasing the ER- subpopulation, perhaps spawning acquired heterogeneity. Our goal here has been to discover drugs for treatment of luminal cancers that would suppress the intrinsic or acquired ER-PR-CK5+ subpopulation when combined with standard endocrine therapies. For that we needed pure luminal-derived ER-PR-CK5+ cells for drug screening, that is, the pLB cells reported here (Figure 1).

\section{Luminal tumor-cell heterogeneity}

Assessment of intratumoral heterogeneity requires cellby-cell or microdissection methods that do not assume a tumor is a uniform mass of identical cells. This is in contrast to studies using bulk tumor DNA, RNA or protein for analysis of gene expression patterns, mutation spectra, copy number changes, et cetera. [24]. Although the latter clearly show that even within major breast cancer subtypes like luminal there are clinically important subsets that modify patient outcome and necessitate unique therapeutic approaches, they do not address intratumoral cell heterogeneity. Some studies have used laser capture microdissection to demonstrate intratumoral cytogenetic heterogeneity [25], or heterogeneity of $c$-myc, cyclinD1 [26], HER2 [27] or ER [28] expression. We used
ER/PR and CK5 as markers to show that significant cellular variability exists within and between luminal tumors [12] with ER-PR-CK5+ cells interspersed among the $\mathrm{ER}+\mathrm{PR}+\mathrm{CK} 5-$ cells in more than $50 \%$ of cases. Clearly this presents significant diagnostic and therapeutic challenges, including the risk of flawed prognostic estimates and inadequate treatment based on reliance on a single, possibly unrepresentative, biopsy. Transcending these is the failure to treat subpopulations of tumor cells that are not identified by current assays [23,29-31].

\section{Modeling luminal heterogeneity}

Here we developed pure ER+PR+CK5- and ER-PR-CK5+ cell lines derived from the same parental luminal precursor that allow us to reconstruct intratumoral heterogeneity while tightly controlling the ratio of these two cell populations. Among other things, we needed to control luminobasal cell numbers because they are often sparse in untreated mixed-cell luminal cancers. Additionally, although the origins of intratumoral heterogeneity remain unclear, with both cancer stem cell and clonal evolution hypotheses proffered, in either scenario cell variability is posited to originate from a single cell [29]. This renders the progeny genetically identical. We sought to model this property as well. To our knowledge pLUM and pLB represent rare examples of natural isogenic cells exhibiting substantive phenotypic differences. To generate them, fixed CK5- and CK5+ cells sorted by FACS from the same tumor xenograft were profiled to discover genes that encode cell-surface proteins and discriminate between the two populations [13]. This allowed us to develop a novel FACS-based scheme using CLD3 and CD49f to separate the two cells from a parentalcell mixture in a sterile, live state (Figure 1). Successive purifications yielded highly pure cell lines that maintain pLUM or pLB phenotypes in culture and provide a stable resource for modeling and manipulating heterogeneity. As the cells share a common progenitor and exhibit little genetic divergence [13] this limits the influence of unique mutations on their biological behavior and response to drugs.

\section{Luminal cells suppress luminobasal cells}

Clinical evidence [12], in vitro three-dimensional colonies (Figure 3) and in vivo solid tumor xenografts (Figure 2) demonstrate that luminal and luminobasal cells in a 
mixed-cell microenvironment behave differently than the same cells in pure states, suggesting that there is crosstalk between them. Heterogeneous mixed-cell xenografts are larger but more necrotic than their homogenous purecell counterparts (Figure 2). In mixed three-dimensional colonies, pLUM proliferation is stimulated by presence of pLB cells (Figure 3) or by LB-conditioned media (Figure 3D). The soluble factors involved are unknown but could include insulin-like growth factors known to be high in ERcells, low or absent in ER+cells, but induce ER and promote ER+tumor growth [32,33]. In contrast pLB cell proliferation is suppressed by neighboring pLUM or MCF7 cells (Figure 3), which also involves secreted factors (Figure 3D). The paracrine-acting inhibitory factors are also unknown but could include transforming growth factor (TGF)- $\beta[34,35]$. The findings of LB suppression by LUM, plus our clinical data showing that luminobasal cells are upregulated in tumors of tamoxifen-treated patients [12] present a troubling scenario. Namely, that prior to antiestrogen therapy a minor intrinsic luminobasal subpopulation is suppressed by dominant neighboring luminal cells. However, as antiestrogens shrink inhibitory signals coming from the luminal population, the luminobasal population expands; this is an illustration of inadvertent therapy-induced enrichment $[33,36]$. These findings underscore the impact that intratumoral cellular dynamics have on the success (or failure) of endocrine therapies in heterogeneous tumors, prompting us to seek drugs that directly target the ER-CK5+ subpopulation.

\section{Combination therapy targeting Luminal tumor heterogeneity}

To find drugs that suppress the luminobasal subpopulation, co-cultured pLUM and pLB cells were arrayed and screened for pLB-specific drugs using a library of 89 FDA-approved and well-characterized oncology therapeutics. The two EGFRi in the library, gefitinib and erlotinib, were highly pLB-specific. This was in contrast, for example, to the EGFR/HER2 inhibitor lapatinib, which showed no selectivity (Figure 4 and Additional file 2: Table S2). Identification of EGFRi as luminobasal-specific agents led us to analyze a dual antiestrogen/EGFRi combination that simultaneously targets pLUM and pLB in mixed-cell three-dimensional colonies (Figure 5A, 5B) and xenografts (Figure $5 \mathrm{C}$ ). We observed a strong response to brief gefitinib treatment, even in the presence of fulvestrant, demonstrating that the EGFRi is bioactive in combination with an antiestrogen.

Clinically, EGFRi monotherapy or antiestrogen/EGFRi combinations have yielded mixed results. In advanced luminal disease previously treated with antiestrogens, gefitinib had no detectable benefit, perhaps because the tumors contained few EGFR+ cells [37]. On the other hand, in metastatic disease, Cristofanilli et al. observed that gefitinib in conjunction with anastrozole prolonged progression-free survival [38]. With regard to therapy for early stage disease, addition of gefitinib to anastrozole failed to improve outcome in one study [39], while in another, gefitinib combined with tamoxifen was beneficial in previously untreated patients [40]. Clinical benefits of EGFR inhibition may stem from delaying acquisition of hormone resistance [38] or from blocking proliferative growth factor signaling in tumors with EGFR+ cells. In support of this, neoadjuvant treatment of primary tumors with gefitinib or gefitinib plus anastrozole in a postmenopausal, EGFR+ cohort reduced proliferation, EGFR activation and tumor size [41]. We propose that response to combination endocrine/EGFRi therapies in ER+ luminal cancers may improve long-term survival in patients whose tumors have been preselected [42] for presence of a luminobasal subpopulation based on ER/PR, CK5 and EGFR biomarker expression.

\section{Conclusions}

Currently, the ER-PR-CK5+ cells of luminal breast cancers are not treated. They are malignant, indolent and antiestrogen-resistant; they expand in response to endocrine or chemotherapies [21]; at least a subset has tumorinitiating capacity $[12,13,43]$. We now show that in mixedcell experimental models, the ER-PR-CK5+ population can be suppressed by EGFRi and that combination endocrine/ EGFRi therapies may additively target $\mathrm{ER}+\mathrm{PR}+\mathrm{CK} 5-$ and ER-PR-CK5+ subpopulations. Clinically, luminal breast cancers exhibiting the appropriate heterogeneity for treatment by this combination could be easily identified using ER/PR and CK5 or EGFR as biomarkers. As EGFRi are already approved for oncology use, the combination therapies we propose can be immediately translated to clinical trials.

\section{Additional files}

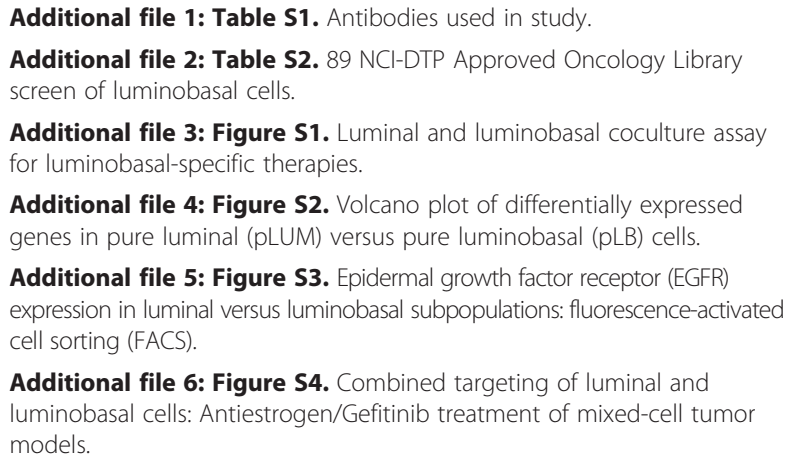

Additional file 3: Figure S1. Luminal and luminobasal coculture assay for luminobasal-specific therapies.

Additional file 4: Figure S2. Volcano plot of differentially expressed genes in pure luminal ( $p L U M)$ versus pure luminobasal ( $p L B$ ) cells.

Additional file 5: Figure S3. Epidermal growth factor receptor (EGFR) expression in luminal versus luminobasal subpopulations: fluorescence-activated cell sorting (FACS).

Additional file 6: Figure S4. Combined targeting of luminal and luminobasal cells: Antiestrogen/Gefitinib treatment of mixed-cell tumor models.

\section{Abbreviations}

BrdU: bromodeoxyuridine; CK5: cytokeratin 5; CM: conditioned media; DAPI: 4',6-diamidino-2-phenylindole; DMEM: Dulbecco's modified Eagle's medium; DMSO: dimethyl sulfoxide; E: estrogen; EGFR: epidermal growth factor receptor; EGFRi: epidermal growth factor receptor inhibitor; ER: estrogen receptor; EWD: estrogen withdrawn; FACS: fluorescence-activated cell sorting; 
FBS: fetal bovine serum; GF: growth factor; ICl: ICI 182 780, fulvestrant; HER2: human epidermal growth factor receptor-2; IHC: immunohistochemistry; NSG (NOD SCIDY): non-obese diabetic/severe combined immunodeficient; ovx'd: ovariectomized; P: progesterone; pLB: pure luminobasal; pLUM: pure luminal; PR: progesterone receptor; STR: short tandem repeats; TN: triple negative; ZsG: ZsGreen

\section{Competing interests}

The authors declare that they have no competing interests.

\section{Authors' contributions}

AJK, ALS, MPP, JMH, BSB, HAH and KBH designed experiments. JMH and BSB generated and analyzed the new pLUM and pLB cell-lines. MPP and $\mathrm{HAH}$ performed the microarray profiling and analyses. MPP conducted three-dimensional mixed-cell and conditioned media experiments. AJK carried out drug screening studies. ALS and BSB managed mouse tumor xenograft models and processed tumor samples. AJK, ALS and KBH wrote and revised the manuscript. KBH directed these studies. All authors read and approved the final manuscript.

\section{Authors' information}

Aaron J Knox and Allison L Scaling: first authors.

\section{Acknowledgements}

This study was supported by NIH R01 CA026869-35, the Breast Cancer Research Foundation and the National Foundation for Cancer Research (to KBH). We thank the University of Colorado's School of Pharmacy High Throughput Screening Core Facility and Cancer Center Flow Cytometry Lab and Histology Shared Resource Facility.

\section{Author details}

'Department of Medicine, Division of Endocrinology, Metabolism and Diabetes, University of Colorado Anschutz Medical Campus, 12801 E. 17th Ave, Aurora, CO 80045, USA. ${ }^{2}$ Departments of Pathology, University of Colorado Anschutz Medical Campus, Aurora, CO 80045, USA. ${ }^{3}$ Universidad Andrés Bello, School of Medicine, Center for Integrative Medicine and Innovative Science (CIMIS), Santiago, Chile. ${ }^{4}$ School of Biological Sciences, University of Northern Colorado, Greeley, CO 80639, USA.

Received: 11 February 2014 Accepted: 22 July 2014

Published: 13 August 2014

\section{References}

1. Nadji M, Gomez-Fernandez C, Ganjei-Azar P, Morales AR: Immunohistochemistry of estrogen and progesterone receptors reconsidered: experience with 5,993 breast cancers. Am J Clin Pathol 2005, 123:21-27.

2. Ali $\mathrm{S}$, Coombes RC: Endocrine-responsive breast cancer and strategies for combating resistance. Nat Rev Cancer 2002, 2:101-112

3. Hammond ME, Hayes DF, Wolff AC, Mangu PB, Temin S: American society of clinical oncology/college of american pathologists guideline recommendations for immunohistochemical testing of estrogen and progesterone receptors in breast cancer. J Oncol Pract 2010, 6:195-197.

4. Collins LC, Botero ML, Schnitt SJ: Bimodal frequency distribution of estrogen receptor immunohistochemical staining results in breast cancer: an analysis of 825 cases. Am J Clin Pathol 2005, 123:16-20.

5. Mohsin SK, Weiss H, Havighurst T, Clark GM, Berardo M, le Roanh D, To TV Qian Z, Love RR, Allred DC: Progesterone receptor by immunohistochemistry and clinical outcome in breast cancer: a validation study. Mod Pathol 2004, 17:1545-1554.

6. Perou CM, Sorlie T, Eisen MB, van de Rijn M, Jeffrey SS, Rees CA, Pollack JR, Ross DT, Johnsen $\mathrm{H}$, Akslen LA, Fluge O, Pergamenschikov A, Williams C, Zhu SX, Lonning PE, Borresen-Dale AL, Brown PO, Botstein D: Molecular portraits of human breast tumours. Nature 2000, 406:747-752.

7. Weigelt B, Mackay A, A'hern R, Natrajan R, Tan DS, Dowsett M, Ashworth A, Reis-Filho JS: Breast cancer molecular profiling with single sample predictors: a retrospective analysis. Lancet Oncol 2010, 11:339-349.

8. Blows FM, Driver KE, Schmidt MK, Broeks A, van Leeuwen FE, Wesseling J, Cheang MC, Gelmon K, Nielsen TO, Blomqvist C, Heikkila P, Heikkinen T, Nevanlinna H, Akslen LA, Begin LR, Foulkes WD, Couch FJ, Wang X, Cafourek V, Olson JE, Baglietto L, Giles GG, Severi G, McLean CA, Southey MC, Rakha E, Green AR, Ellis IO, Sherman ME, Lissowska J, et al: Subtyping of breast cancer by immunohistochemistry to investigate a relationship between subtype and short and long term survival: a collaborative analysis of data for 10,159 cases from 12 studies. PLoS Med 2010, 7:e1000279.

9. Cheang MC, Voduc D, Bajdik C, Leung S, McKinney S, Chia SK, Perou CM, Nielsen TO: Basal-like breast cancer defined by five biomarkers has superior prognostic value than triple-negative phenotype. Clin Cancer Res 2008, 14:1368-1376.

10. Kreso A, O'Brien CA, van Galen P, Gan Ol, Notta F, Brown AM, Ng K, Ma J, Wienholds E, Dunant C, Pollett A, Gallinger S, McPherson J, Mullighan CG, Shibata D, Dick JE: Variable clonal repopulation dynamics influence chemotherapy response in colorectal cancer. Science 2013, 339:543-548.

11. Marusyk A, Polyak K: Cancer. Cancer cell phenotypes, in fifty shades of grey. Science 2013, 339:528-529.

12. Kabos P, Haughian JM, Wang X, Dye WW, Finlayson C, Elias A, Horwitz KB, Sartorius CA: Cytokeratin 5 positive cells represent a steroid receptor negative and therapy resistant subpopulation in luminal breast cancers. Breast Cancer Res Treat 2011, 128:45-55.

13. Haughian JM, Pinto MP, Harrell JC, Bliesner BS, Joensuu KM, Dye WW, Sartorius CA, Tan AC, Heikkila P, Perou CM, Horwitz KB: Maintenance of hormone responsiveness in luminal breast cancers by suppression of Notch. Proc Natl Acad Sci U S A 2012, 109:2742-2747.

14. Horwitz KB, Mockus MB, Lessey BA: Variant T47D human breast cancer cells with high progesterone-receptor levels despite estrogen and antiestrogen resistance. Cell 1982, 28:633-642.

15. Harrell JC, Dye WW, Allred DC, Jedlicka P, Spoelstra NS, Sartorius CA, Horwitz KB: Estrogen receptor positive breast cancer metastasis: altered hormonal sensitivity and tumor aggressiveness in lymphatic vessels and lymph nodes. Cancer Res 2006, 66:9308-9315.

16. Barrett MT, Glogovac J, Prevo L, Reid BJ, Porter P, Rabinovitch PS: High-quality RNA and DNA from flow cytometrically sorted human epithelial cells and tissues. BioTechniques 2002, 32:888-890.

17. Pinto MP, Jacobsen BM, Horwitz KB: An immunohistochemical method to study breast cancer cell subpopulations and their growth regulation by hormones in three-dimensional cultures. Front Endocrinol (Lausanne) 2011, 2:15.

18. Harrell JC, Dye WW, Harvell DM, Pinto M, Jedlicka P, Sartorius CA, Horwitz KB: Estrogen insensitivity in a model of estrogen receptor positive breast cancer lymph node metastasis. Cancer Res 2007, 67:10582-10591.

19. Rana P, Sridhar SS: Efficacy and tolerability of lapatinib in the management of breast cancer. Breast Cancer (Auckl) 2012, 6:67-77.

20. van de Rijn M, Perou CM, Tibshirani R, Haas P, Kallioniemi O, Kononen J, Torhorst J, Sauter G, Zuber M, Kochli OR, Mross F, Dieterich H, Seitz R, Ross D, Botstein D, Brown P: Expression of cytokeratins 17 and 5 identifies a group of breast carcinomas with poor clinical outcome. Am J Pathol 2002 161:1991-1996.

21. Haque R, Ahmed SA, Inzhakova G, Shi J, Avila C, Polikoff J, Bernstein L, Enger SM, Press MF: Impact of breast cancer subtypes and treatment on survival: an analysis spanning two decades. Cancer Epidemiol Biomarkers Prev 2012, 21:1848-1855.

22. Giordano C, Cui Y, Barone I, Ando S, Mancini MA, Berno V, Fuqua SA: Growth factor-induced resistance to tamoxifen is associated with a mutation of estrogen receptor alpha and its phosphorylation at serine 305 . Breast Cancer Res Treat 2010, 119:71-85.

23. Polyak K: Heterogeneity in breast cancer. J Clin Invest 2011, 121:3786-3788.

24. Cancer Genome Atlas Network: Comprehensive molecular portraits of human breast tumours. Nature 2012, 490:61-70.

25. Aubele M, Mattis A, Zitzelsberger $H$, Walch A, Kremer M, Hutzler P, Hofler $H$, Werner M: Intratumoral heterogeneity in breast carcinoma revealed by laser-microdissection and comparative genomic hybridization. Cancer Genet Cytogenet 1999, 110:94-102.

26. Glockner S, Buurman H, Kleeberger W, Lehmann U, Kreipe H: Marked intratumoral heterogeneity of c-myc and cyclinD1 but not of c-erbB2 amplification in breast cancer. Lab Invest 2002, 82:1419-1426.

27. Cottu PH, Asselah J, Lae M, Pierga JY, Dieras V, Mignot L, Sigal-Zafrani B, Vincent-Salomon A: Intratumoral heterogeneity of HER2/neu expression and its consequences for the management of advanced breast cancer. Ann Oncol 2008, 19:595-597.

28. Chung GG, Zerkowski MP, Ghosh S, Camp RL, Rimm DL: Quantitative analysis of estrogen receptor heterogeneity in breast cancer. Lab Invest 2007, 87:662-669.

29. Michor F, Polyak K: The origins and implications of intratumor heterogeneity. Cancer Prev Res (Phila) 2010, 3:1361-1364. 
30. Russnes HG, Navin N, Hicks J, Borresen-Dale AL: Insight into the heterogeneity of breast cancer through next-generation sequencing. J Clin Invest 2011, 121:3810-3818.

31. Navin N, Krasnitz A, Rodgers L, Cook K, Meth J, Kendall J, Riggs M, Eberling Y, Troge J, Grubor V, Levy D, Lundin P, Maner S, Zetterberg A, Hicks J, Wigler M: Inferring tumor progression from genomic heterogeneity. Genome Res 2010, 20:68-80.

32. Litzenburger BC, Creighton CJ, Tsimelzon A, Chan BT, Hilsenbeck SG, Wang T, Carboni JM, Gottardis MM, Huang F, Chang JC, Lewis MT, Rimawi MF, Lee AV: High IGF-IR activity in triple-negative breast cancer cell lines and tumorgrafts correlates with sensitivity to anti-IGF-IR therapy. Clin Cancer Res 2011, 17:2314-2327.

33. Freitas DP, Teixeira CA, Santos-Silva F, Vasconcelos MH, Almeida GM: Therapy-induced enrichment of putative lung cancer stem-like cells. Int J Cancer 2013, 134:1270-1278.

34. Knabbe C, Lippman ME, Wakefield LM, Flanders KC, Kasid A, Derynck R, Dickson RB: Evidence that transforming growth factor-beta is a hormonally regulated negative growth factor in human breast cancer cells. Cell 1987, 48:417-428.

35. Fanayan S, Firth SM, Butt AJ, Baxter RC: Growth inhibition by insulin-like growth factor-binding protein-3 in T47D breast cancer cells requires transforming growth factor-beta (TGF-beta) and the type II TGF-beta receptor. J Biol Chem 2000, 275:39146-39151.

36. Pisco AO, Brock A, Zhou J, Moor A, Mojtahedi M, Jackson D, Huang S: Non-Darwinian dynamics in therapy-induced cancer drug resistance. Nat Commun 2013, 4:2467.

37. Baselga J, Albanell J, Ruiz A, Lluch A, Gascon P, Guillem V, Gonzalez S, Sauleda S, Marimon I, Tabernero JM, Koehler MT, Rojo F: Phase II and tumor pharmacodynamic study of gefitinib in patients with advanced breast cancer. J Clin Oncol 2005, 23:5323-5333.

38. Cristofanilli M, Valero V, Mangalik A, Royce M, Rabinowitz I, Arena FP, Kroener JF, Curcio E, Watkins C, Bacus S, Cora EM, Anderson E, Magill PJ: Phase II, randomized trial to compare anastrozole combined with gefitinib or placebo in postmenopausal women with hormone receptor-positive metastatic breast cancer. Clin Cancer Res 2010, 16:1904-1914.

39. Smith IE, Walsh G, Skene A, Llombart A, Mayordomo JI, Detre S, Salter J, Clark E, Magill P, Dowsett M: A phase II placebo-controlled trial of neoadjuvant anastrozole alone or with gefitinib in early breast cancer. J Clin Oncol 2007, 25:3816-3822.

40. Osborne CK, Neven P, Dirix LY, Mackey JR, Robert J, Underhill C, Schiff R, Gutierrez C, Migliaccio I, Anagnostou VK, Rimm DL, Magill P, Sellers M: Gefitinib or placebo in combination with tamoxifen in patients with hormone receptor-positive metastatic breast cancer: a randomized phase II study. Clin Cancer Res 2011, 17:1147-1159.

41. Polychronis A, Sinnett HD, Hadjiminas D, Singhal H, Mansi IL, Shivapatham D, Shousha S, Jiang J, Peston D, Barrett N, Vigushin D, Morrison K, Beresford E, Ali S, Slade MJ, Coombes RC: Preoperative gefitinib versus gefitinib and anastrozole in postmenopausal patients with oestrogen-receptor positive and epidermal-growth-factor-receptor-positive primary breast cancer: a double-blind placebo-controlled phase II randomised trial. Lancet Oncol 2005, 6:383-391.

42. Montemurro F, Rossi V, Geuna E, Valabrega G, Martinello R, Milani A, Aglietta M: Current status and future perspectives in the endocrine treatment of postmenopausal, hormone receptor-positive metastatic breast cancer. Expert Opin Pharmacother 2012, 13:2143-2156.

43. Horwitz KB, Dye WW, Harrell JC, Kabos P, Sartorius CA: Rare steroid receptor-negative basal-like tumorigenic cells in luminal subtype human breast cancer xenografts. Proc Natl Acad Sci U S A 2008, 105:5774-5779.

doi:10.1186/s13058-014-0418-6

Cite this article as: Knox et al:: Modeling luminal breast cancer heterogeneity: combination therapy to suppress a hormone receptor-negative, cytokeratin 5-positive subpopulation in luminal disease. Breast Cancer Research 2014 16:418.

\section{Submit your next manuscript to BioMed Central and take full advantage of:}

- Convenient online submission

- Thorough peer review

- No space constraints or color figure charges

- Immediate publication on acceptance

- Inclusion in PubMed, CAS, Scopus and Google Scholar

- Research which is freely available for redistribution

Submit your manuscript at www.biomedcentral.com/submit 